\title{
Decline in the Quality of Urban Life in Selected Oil- Rich Cities in the Niger Delta: A Retarded Discernment or Denied Reality
}

\author{
Brown, Ibama ${ }^{1 *}$ and Dapa, Idaminabo Nengi ${ }^{1}$ \\ ${ }^{1}$ Department of Urban and Regional Planning, Rivers State University, Port Harcourt, Nigeria.
}

Authors' contributions

This work was carried out in collaboration between both authors. Author BI designed the study, performed the statistical analysis, wrote the protocol and wrote the first draft of the manuscript. Author DIN managed the literature searches and analyses of the study. Both authors read and approved the final manuscript.

Article Information

DOI: $10.9734 / A J G R / 2020 / v 3 i 330111$ Editor(s):

(1) Dr. Armando García Chiang, Universidad Autónoma Metropolitana-Iztapalapa, México. Reviewers:

(1) Abebaw Andarge Gedefaw, Debre Markos University, Ethiopia and University of Natural Resources and Life Sciences, Austria. (2) Souhaila Bendjedidi, Biskra University, Algeria.

(3) Peeyush Gupta, India. Complete Peer review History: http://www.sdiarticle4.com/review-history/59209

Original Research Article

Received 14 June 2020

Accepted 19 August 2020

Published 01 September 2020

\begin{abstract}
This research was to evaluate the quality of life of the urban dwellers in Yenagoa, Amarata and Ekeki cities to ascertain if there is a decline in the quality of life residents in those selected neighbourhoods with a view to highlight such causal factors. The study adopted the PassiveObservational survey design such that the research respondents were observed in-situ without experimental manipulation. The research population was purposively drawn, and data was drawn from primary and secondary sources. Objective and subjective dimensions of quality of life were viewed in the form of physical, social and economic domains were assessed with emphasis on the type of housing, recreational preferences and employment status of respondents. Findings indicate that the quality of life of residents in Yenagoa, Amarata and Ekeki has progressively declined from when Yenagoa was a local government headquarters to becoming a capital city of an oil and gas producing state. As evident, the predominant housing type is rooming housing that does not befit its status, with limited recreational space and a phenomenal $45 \%$ unemployment rate. Findings further
\end{abstract}


depict a bleak and rapidly declining quality of life of residents. The study recommends that there should be deliberate government intervention to improve housing conditions, provision of adequate functional recreational facilities that would enhance social interaction and physical wellbeing. There should be deliberate government policy with the requisite framework to stimulate industrial growth to reduce the phenomenal unemployment were recommended.

Keywords: Decline; quality of life; retarded discernment; Niger Delta; denied reality.

\section{INTRODUCTION}

Cities globally are inundated with a plethora of challenges amongst those are insufficient and sometimes overburdened public utilities and services with a tainted sense of place, abysmal security system and separation in land uses. Others include enormous unemployment and poor literacy levels. These negativities oftentimes affect the quality of life and living conditions of most urban dwellers. Yenagoa as a city has over the years witnessed incremental changes in its landscape from when it was a local government headquarters to when it attained a capital city status. There have been strands of evidence that indicate the rapid emergence of unplanned and uncontrolled urbanisation in the global south [1]. Such a rapid urbanisation process in most circumstances engender social and economic growth [2]. The city of Yenagoa and environs fit into these descriptions of rapid uncontrolled urbanisation and pockets of social and economic growth. This development has also taken its toll by engendering a myriad of complex environmental issues raised in the foregoing and has a palpable decline in the quality of life of residents. The Quality of life (QoL) paradigm oftentimes deploy comparative and analytical studies to expose existing inequalities between inter and intra residential neighbourhoods in some urban centres. These inequalities have led to the divergence of attention on some factors affecting the perceived satisfaction of residents. Assessing the QoL of intra-urban residents provides an insight into the perceived level of satisfaction and/or dissatisfaction experienced in a neighbourhood because QoL in its broad sense is dependent on the overall comfort including the social, physical, mental and environmental fabric of neighbourhoods. In most cases declining QoL is the implications of hasty urbanisation and its associated challenges in Nigeria that are relatively prevalent over the years [3].

Quality of life in some communities hosting oil and gas-related facilities in the Niger Delta region of Nigeria has been a source of concern due to its downward spiral hinged on the presence and activities of oil and gas resources and multinationals in these communities. Over the years these host communities have suffered palpable neglect from oil and gas multinationals operating in their communities. Such palpable neglect has caused a plethora of impediments in these communities to the extent of negatively affecting their sources of livelihood, income, and occupation with destruction and distortion of the existing ecosystem balance [4]. Bayelsa State is among the league of states in Nigeria playing host to oil and gas multinationals. It is a coastal state inundated with a myriad of rivers, streams and creeks emptying into the Atlantic Ocean. Most of its population are predominantly fisherfolks who live mostly in rural areas despite being an oil producing state in Nigeria. Granted that status, emerging developments (physical, social and economic) over the years in some neighbourhoods in Yenagoa capital city have engendered continuous stream of rural-urban migrants as these neighbourhoods gradually metamorphose into urban towns. These urban towns beside hosting oil and gas multinationals, also play host to educational institutions such as Universities, Polytechnics, Colleges of Education and other ancillary services which implicitly indicate a massive influx of people and activities. Prior the emergence of Yenagoa attaining its capital city status, it was a local government headquarters that witnessed rapid urbanisation alongside other contiguous towns such as Amarata and Ekeki which has contributed to the soaring cost of living and subsequent decline in the quality of urban life as most residents could not afford the basics of life.

With such phenomenal influx of people into the capital city and its adjoining urban towns occasioned by the presence of oil and gas production activities, tourism potentials and rapid urbanisation, there is a rapid decline in the quality of life of the residents. This decline in the quality of urban life is engendered by an unprecedented spike in the cost of living; increased rental values, surges in crime rate, generation of more domestic and industrial wastes and increased human and vehicular traffic leading up to congestion. Also, instances 


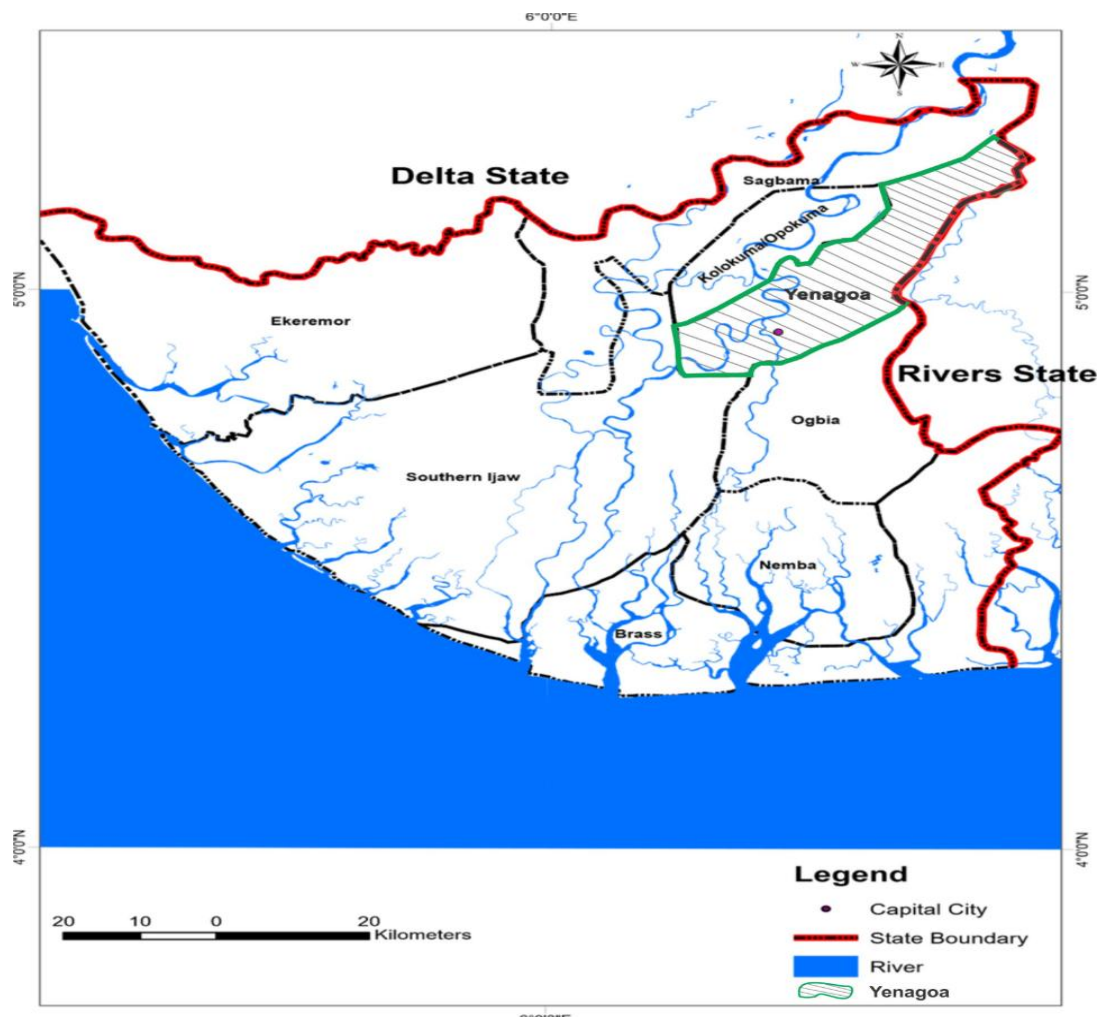

Fig. 1. Map of Bayelsa State showing Yenagoa City LGA, the study area Source: Surveyor General Office, Bayelsa State, 2019

of overpopulation, pressure on existing social amenities and limited job opportunities for the teeming population has contributed significantly to the rapid decline in the quality of life of the residents as existing facilities and infrastructure have been stretched to the limits.

This study aims to assess the quality of life of residents in Yenagoa, Amarata and Ekeki urban towns from with a view to identifying causal factors and probable solutions to improve on the declining quality of life.

The objectives are stated as follows;

- To identify the probable positive and negative causes of the declining quality of life of residents in the study area

- Ascertain the overall rating of the quality of life in the study area by residents.

\subsection{Presentation of the Study Area}

Yenagoa is a local government area and a city in Bayelsa State in the Niger Delta which lies south of the area at $4^{\circ} 55^{\prime} 29^{\prime \prime} \mathrm{N} 6^{\circ} 15^{\prime} 51^{\prime \prime} \mathrm{E}$. It is one of
Nigeria's fast-growing cities after it became the capital city of Bayelsa State in 1996. Yenagoa has since become a major hub of activities and a new frontier of opportunity for a varied range of economic, social and political interests. The greatest part of Yenagoa's population was composed of what may be called short-distance migrants from the numerous districts of eastern Nigeria. Other long-distance migrants of diverse ethnic groups are the Hausas, Fulanis, Yorubas, Edos, and other related groups were amply represented in the early days of the city. Yenagoa city today is a major educational and administrative centre and an emerging industrial hub since it hosts some of the nation's multinational oil and gas exploration and production companies [5]. The local government area has an area of $706 \mathrm{~km}^{2}$ and a population of 352,285 at the 2006 census (National population commission, 2006).

\section{THEORETICAL AND CONCEPTUAL FRAMEWORK}

This study is viewed from the lens of quality of life concept looking at the physical, social and economic domains. 


\subsection{Conceptual Definition of Quality of Life (QoL)}

Quality of Life (QoL) is a multidisciplinary and multifaceted concept with a plethora of attempts to define it. [6] as well as other researchers assessing and evaluating QoL agree that the concept elicits widespread interest, but it is by no means precisely defined. In support of this assertion, [7] and [8] posit that all the definitions of QoL are based on well-thought-out issues that tend to measure and consequently explain the extent of individual happiness and state of wellbeing in any society. The nexus in the definitions relating to QoL is the application of variables and indicators that look at specific QoL indices such as physical, economic and social extents of individuals and societies notwithstanding their status on the development scale. Applicability of these indicators varies from country to country based on social, economic and other compelling considerations like access to available data and level of development. The concept of QoL remains mainly theoretical as it contains a large element of subjectivity and thus it is difficult for it to be treated as an unambiguously measurable dimension [9]. Emerging research on QoL has focused on two rudimentary methodologies of measurement. The first termed "subjective wellbeing" which focuses upon self-reported levels of happiness, pleasure, fulfilment and the like. The latter utilises "objective" measurement of QoL such as generally quantifiable indices of social, economic and health indicators as prescribed by the UNDP in 1998 [10]. Furthermore, the approach reflects more on the extent to which human needs are or can be met. Quality of Life could be translated into the liveability of a place; indicating that in an urban society, QoL relates to the common experiences of urban residents and the ability of the city to meet liveability needs. Besides, the perception of people regarding their environment may differ based on the diversity of their cultural and social orientation and circumstances [11].

\subsection{Standard Quality of Life}

Contextually, standard Quality of Life refers to the content of its operational construct. This construct as identified by QoL researchers [12]; [13] would include an understanding of the dimensions of QoL and the delineation of selected indicators and domains for measuring the QoL in the selected areas. It is imperative to note that as already stated above there are a variety of dimensions for explaining and understanding QoL assessment.

\subsection{Dimensions of Quality of Life}

Dimensions of QoL in any assessment takes into cognisance of both subjective and objective assessment methods. Subjective assessment method of QoL assesses and evaluates the mental state of individuals, individual and group perception of the quality of urban life [14]. In the opinion of [15], quality of life has three dimensions: religious, philosophical and cultural (which includes, happiness, the fulfilment of needs, functioning in a social context, etc.). This study, however, considers the conventionally accepted dimensions - subjective and objective. A combination of subjective and objective QoL paradigms develop useful indices that enable the evaluation, measurement and assessment of the QoL in cities. This combination provides city managers, stakeholders and policymakers the opportunity to clearly define planning framework and urban development policies towards achieving effective urban management by rating cities across the spectrum in relation to their global competitiveness.

\subsection{Subjective Dimension}

According to [15] subjective QoL revolves around individual feelings such as individual contentment with life and subjective happiness. Subjective assessment method further advances qualitative indicators to evaluate and measure the concept of QoL since subjective indicators are social in nature and include income, property, employment and environmental quality of residential neighbourhoods, social interactions, physical and mental health, education and recreation [16]. There is a consensus on this dimension of life quality. Notable researchers agree that the assessment of the QoL is also dependent on the individual's subjective evaluation of his immediate environment [6]. [17] further conceptualises that subjective urban QoL refers to individual satisfaction with urban domains such as housing, neighbourhood, community and regional. Drawing on the research of [18], subjective QoL is a reflection of the individual's perception of his immediate environment in relation to the level of satisfaction and happiness which includes three interrelated components: life satisfaction (cognitive sense of satisfaction with life), pleasant and unpleasant affective (emotional) experiences of the individual. 


\subsection{Objective Dimension}

Objective assessment of QoL assesses and evaluates professional opinions based on the availability of basic governance structure and indispensable services relating to urban life. As such, objective indicators assess the environment and living conditions concerning the adequacy of infrastructure and services such as healthcare, energy, education, transportation and population density as against specific environmental quality like water and air in addition to housing quality, rule of law and governance style [14]. Furthermore, the objective dimension of QoL entails several objective characteristics of the urban environment, often with objective indicators to generate an objective quality of urban life index for ranking places [6]. Also, [19] assert that the objective dimension of QoL has indicators based on quantitative statistics of urban environment characteristics that fulfil the basic resident's needs.

\subsubsection{Quality of life domains}

Opinions of QoL experts indicate that there are some determinants of residential QoL and [22] identifies several of such domains that are common to most QoL studies. These domains include social, urban, economic and public domains.

\subsection{Quality of Life and Urban Planning}

Urban planning is viewed as a political and technical process with a vested interest in the design of the urban environment, control the use of land in addition to transportation routes and orderly development of communities and settlements [19]. It is believed that an allinclusive notion of quality of life holds important opportunities for planning because until recently, urban planners have focused largely on individual elements of quality of life such as transportation or housing [20]. This is evident in most planning statements and projects that identify QoL as either the outcome of conditions - economic, environmental, social, aesthetic, civic, etc. and/or the causes of impressions about QoL. From the foregoing, these impressions could influence perceived or actual prosperity and attractiveness of a place [21]. Contextually QoL in planning relates to the review of contemporary planning theories and approaches. Some of these include New Urbanism, Smart
Growth, Compact Cities, Green Infrastructure, neo-traditional planning, sustainable development [22].

\subsection{Quality of Life Surveys}

The study of Quality of Life in planning in most circumstances hinges largely on the assumption that variations in QoL among individuals, groups or places can be identified and that prescriptive measures could or should be taken to eradicate the differences among individuals and groups [21]. To assess and measure the QoL in urban areas, [22] identified different approaches for measuring and assessing urban QoL and evaluate the residential quality of life of residents in some informal settlements in Port Harcourt municipality. One of such approaches identified indicated that [23] hedonic equilibrium model in obtaining the quality of life ranking of six cities in Southern Ontario, Canada namely: Guelph, Kitchener, London, Sarnia, St. Catherine and Windsor prove to be very handy. The approach employed a structural approach found that residential quality of life is a function of housing and neighbourhood characteristics (number of rooms, age of the house, crime rate, air quality and mean annual temperature) [22].

The Hedonic model has been used in many studies to estimate the quality of life ranking of several cities and to examine the relative influence of cultural amenities, prestigious schools' accessibility, mixed land uses, socioeconomic factors and housing characteristics on the price structure of residential property [13]. This model was estimated using census tract data for the six cities. The study further revealed that each of the six cities provides a different QoL distribution to its residents. Other approaches identified for assessing life quality includes Life Satisfaction Approach (LSA), a combination of the Hedonic approach and the Life Satisfaction Approach, the Conjoint Analysis Approach, Analytical Hierarchy Process Approach (AHP), and Analytical Network Approach (ANP) [13].

\subsection{Some Global Patterns of Quality of Life}

[21] has analysed the prevalent conditions of the world considering patterns and stated that should the population of the world be reduced to a village with 100 people and the same global ratios were preserved then we would find: 
Table 1. Quality of life domains

\begin{tabular}{|c|c|c|c|}
\hline Social Domain & Urban Domain & Economic Domain & Public Domain \\
\hline Education & Housing & Work/employment & $\begin{array}{l}\text { Political rights and } \\
\text { general values }\end{array}$ \\
\hline Leisure & Land use & Consumption & Government \\
\hline Health & Transportation & Food/ nutrition & Justice \\
\hline Social environment/stability & Physical environment & & \\
\hline $\begin{array}{l}\text { Public security/ crime and } \\
\text { safety }\end{array}$ & Natural environment & & \\
\hline $\begin{array}{l}\text { Social opportunity/ } \\
\text { participation }\end{array}$ & $\begin{array}{l}\text { Recreation and } \\
\text { culture }\end{array}$ & & \\
\hline Community stress & Population resources & & \\
\hline Community affordability & Government services & & \\
\hline Social well-being & $\begin{array}{l}\text { Education and health } \\
\text { services }\end{array}$ & & \\
\hline
\end{tabular}

57 Asians;

21 Europeans

14 from the Western Hemisphere

8 Africans

52 women and 48 men

6 people would possess $59 \%$ of the entire world's wealth, and the 6 would be from the USA

80 would live in substandard housing

70 would be unable to read

50 would suffer from malnutrition

1 would be near death

1 would have a college education

1 would own a computer

The interesting dynamic is that as QoL increases in one place this can reflect an increase in differences among places in terms of QoL the inequalities are more and more pronounced. According to the World Bank (2011) report estimates, over $90 \%$ of urban growth occurs in the developing world, adding an estimated 70million new residents to urban areas each year. During the next two decades, the urban population of the world's two poorest regions South Asia and Sub-Saharan is expected to double [24].

\subsection{Quality of Life Surveys in Asia}

[25] assesses QoL in Asia with emphasis on the challenges evident in some urban centres in South-East Asia. South-East Asia is perceived to be a diverse sub-region of Asia, with an extensive diversity within the region. It includes a very populous country (Indonesia) and a country with a small population (Brunei Darussalam), an economically highly developed country (Singapore) and least developed countries (Cambodia, the Lao People's Democratic
Republic and Myanmar). South-East Asia is steadily urbanising with an urban population increase from $15.5 \%$ in 1950 to $41.8 \%$ (about 250 million people) and an expected increase to $50 \%$ by 2025 . Furthermore, during the World Habitat Day (2014) celebration, indications emerged from a UN-Habitat report that $30 \%$ of Asia's urban population resides in slums (State of the World Cities Report, 2012/13), and this continent is currently home to half of the urban population of the world [24].

\subsection{Quality of Life Survey-Singapore}

There were large-scale sample surveys of 1093 and 2187 respondents from 81 census divisions in Singapore were conducted in 1997 and 1998, respectively, to measure overall life satisfaction (or quality of life, QoL) as well as levels of importance and satisfaction towards various aspects of life [24]. From the survey, indications emerged that in 1997 the mean QoL score for Singaporeans, or QoL index, was moderately high at 3.61 (using a 5-point Likert scale) but this later dropped by $2 \%$ to 3.55 in 1998 . Issues revolving around the importance and satisfaction with different aspects of life, respondents consistently rated health and family life as more important than other aspects of life, and they were most satisfied with the aspect of family life. Respondents considered aspects of life such as politics, religion and leisure as least important and they were least satisfied with aspects of life such as wealth and consumer goods [26].

\subsection{Quality of Life Survey-Malaysia}

A study conducted in the high density, mixed-use Kuala Lumpur Central area (city centre) 
neighbourhood with one of the six strategic zones in the Kuala Lumpur metropolitan area of Malaysia spanning1,813 hectares. [27] indicate that satisfaction of residents with the overall QoL regarding the location of their neighbourhood is influenced by socio-economic characteristics, life cycle, location of work, and other major facilities such as schools, shopping, family factors. Also notable is the proximity to facilities - shopping services, public transport services, educational services, and workplace. Respondents rated their satisfaction on four graded scales from very dissatisfied to very satisfied. The highest levels of residents' satisfaction concerning neighbourhood physical characteristics including access to public transport services, educational services, availability of good conditions for children, housing quality, greenery, and quietness (mean scores of 3.20 - 3.03) as indicated in Table 2.

Using a Likert rating scale from as 'good' as can be to as 'bad' as can be, respondents were asked to rate their QoL for which more than twothirds of the respondents $(68 \%)$ were satisfied with their overall QoL, while the rest (32\%) expressed their feelings otherwise. Summarily, residents declared their satisfaction with the neighbourhood in terms of the mentioned indicators - the overall residents' quality of life rated as high [27].

\subsection{Quality of Life in Africa}

The UN-Habitat (2014) reports that over half of the urban population $(61.7 \%)$ in Sub-Saharan
Africa resides in slums. Based on the state of the World's Cities Report (2010/11) every year, 10 million or more people are added to the existing urban population of Sub-Saharan Africa and approximately one-third of these, or 3 million moves to formal urban areas and act as both agents and beneficiaries of formal urban and economic growth. The remaining two-thirds, or 7 million, move to informal settlements or slums. Of these, only 2 million can expect to lift themselves out of slum conditions and the other 5 million will remain confined on the wrong side of the urban divide.

\subsection{Quality of Life Survey - South Africa}

In South Africa, more than $32 \%$ of the population resides in only six metropolitan areas, and with rapid urbanisation (exceeding $4 \%$ per annum) the quality of metropolitan city life will increasingly become an indication of the overall QoL in the country. The research employs an index construct for South Africa's six metros consisting of both economic and non-economic QoL indicators, including measures of the quality of the environment and life. Rankings identified for this study of the 6 metropolitan areas range from 1 st to $6^{\text {th }}$ position. Cape Town ranks 1 st, Johannesburg 2nd, Ekurhuleni ranks 3rd and so on. These rankings reveal that despite the rapid urbanisation over decades as South African cities play an important role in improving human QoL. Not only are average incomes in cities much higher than in rural areas in South Africa, but there are also general improvements in the non-economic QoL in the various cities [28].

Table 2. Neighbourhood characteristics

\begin{tabular}{ll}
\hline Neighbourhood Characteristics & $\begin{array}{l}\text { Level of Satisfaction } \\
\text { (Mean Score) }\end{array}$ \\
\hline Housing quality & 3.08 \\
Greenery and quietness & 3.03 \\
Good condition for children & 3.10 \\
Educational services & 3.12 \\
Shopping services & 2.97 \\
Public and private services & 2.90 \\
Proximity to workplace & 3.04 \\
Public transport services & 3.20 \\
Recreational facilities & 2.70 \\
Health services & 2.93 \\
Safety and security & 2.58 \\
Social contact with neighbours & 2.77 \\
Little social cohesion in the neighbourhood & 2.68 \\
\hline
\end{tabular}




\subsection{Quality of Life Survey-Nigeria}

[29] assessed the QoL of poor residential neighbourhoods in Oshogbo, Nigeria. It was deduced that the high cost of housing has forced the increasing population to live in substandard housing and unhealthy conditions giving rise to poor residential neighbourhoods. This study was aimed at identifying the poor residential neighbourhoods in selected areas, examining the characteristics of these neighbourhoods, and examining the socio-economic characteristics of the residents in these selected areas. Results show that poor residential areas are characterized by informal sectors, inadequate access to basic facilities, both social and physical infrastructure and housing finance. Other characteristics identified included, lack or inadequate access to basic public services, substandard housing and inadequate building structures, the illegal subdivision of buildings, poverty, criminality and social exclusion, and unhealthy living conditions. With respect to their socio-economic status, the study revealed that $55 \%$ of the respondents were of low-income status, $25 \%$ were low-medium income, $15 \%$ were upper-medium and only $5 \%$ were high income suggesting that only a few people are comfortable with their income and the deficit are poor.

Similarly, [22] conducted a study in Port Harcourt city (a neighbouring state with similar geography) involved a comparative study of inter-city neighbourhoods both planned and unplanned. Using multistage sampling technique starting from the listing of neighbourhoods in both informal and formal settlements. Listing of buildings, selections of households and respondents to achieve a representative sample of households in each neighbourhood deploying Taro Yamane formula at $10 \%$ level of precision. The selected settlements were Marine Base and Afikpo waterfront settlements identified as informal settlements were examined. Thus, a comparative analysis was carried out to identify specifically residents' perception of their neighbourhood attributes, residents' perception of residential QoL, Perceived Neighbourhood Quality Index (PNQI) and other variables that are important to residents in improving residential QoL in Port Harcourt. Their findings further collaborated [11] position that QoL relates to the common experiences of urban residents and the ability of the city to meet liveability needs because people's perception about their environment differ based on social and cultural environments.

\section{METHODOLOGY}

The study adopted a mixed-method research approach with passive observational survey design and multistage as the subjects were insitu without any experimental manipulation. Each of the urban towns in the study area (Yenagoa, Ekeki and Amarata) was firstly subdivided into sizeable units for ease of access to assess the Quality of Life domains such as the physical, social and economic indicators viewed in the form housing and building quality, neighbourhood quality, social interactions, employment status, nature of livelihoods, community identity and recreational preferences were used for the assessment of Quality of Life of select residents and the sample was drawn purposively from within to get the research population. Data were collected from both primary and secondary sources. The quantitative data collected and analyzed using SPSS and the outcome was displayed descriptively in charts and tables, while the qualitative data was obtained through direct observation and photographs. The purpose of this study was to examine the quality of life of residents to ascertain if there is a decline in the QoL in these select urban towns in relation to the presence of oil and gas multinationals.

\section{FINDINGS AND DISCUSSION}

Findings of the research were categorised according to three domains identified: physical, social and economic domains.

\subsection{Physical Domain}

The built environment of fulfilment and selfconfidence among residents of a city engenders fecund social interactions that further enhance good governance and sustainable urban development and growth [28]. Similarly, environment, health, good attitude and income representing key attributes of social and economic factors evident physically and controlled by individuals also engender good QoL and harnessing those would further enhance QoL. Altering one or all these attributes could lead to a decline in the QoL in such location because without the right attitude, collective services such as management of wastes, neighbourhood security, and the provision of other basic essential neighbourhood services that enhances QoL and individual wellbeing [30]. 
Taking on the dwelling types and condition of the physical domain in QoL literature, this study relies on identifying types of existing dwellings and further harvested the perception and rating of respondents regarding these selected locations.

\subsection{Type of Dwellings}

Table 3 indicates the predominant types of dwellings found in Yenagoa, Amarata and Ekeki respectively. The indicated percentages represent the average drawn on the three settlements. Rooming house (courtyard) has the highest representation in the study area with an average of $52.3 \%$, followed by the Rooming house (wagon) 20.8\%. Some of the other dwelling types are family compound housing with $4.2 \%$, traditional buildings are about $7 \%$, and duplexes and flats are $1.2 \%$ respectively.

From Table 3 it is evident that the predominant type of dwelling unit is the courtyard rooming housing across the study area because it has the highest number of respondents. It represents a deviation from the generalised global assumption that communities playing host to oil and gas multinationals often benefit more in the form of improved physical environmental conditions such as quality housing to assume the least. However, the scenario in these cities in a state playing host to oil and gas multinationals is glaringly different as the predominant housing type found which is part of the physical environment in the study area does not befit the status of an oil producing state neither does it have the characteristics of improved urban quality of life.

It is outrageously bewildering in this $21^{\text {st }}$ century that a capital city and its contiguous towns in an oil and gas producing state in Nigeria would be so inundated with low standard (rooming courtyard) housing as its predominant housing stock. Substandard housing stock as evident from the data indicates a puzzling and underlying social disconnect among the governed, government and the oil and gas multinational which has contributed to magnifying alienation in corporate social responsibility. Social disconnect in this context indicates the failure of the government in providing the necessities of good housing standard. This apparent lack can engender palpable failure in city development and subsequent management. Such housing stock is an indication of a poor economy which often lead up to the poor urban quality of life because most of those houses do not have the basic requirements of standard housing. These basic requirements of a standard housing entail houses with available electricity, water supply, bathroom requirements, indoor flushing toilets, cooking facilities and quality of construction materials [31].

[32] indicate that poor housing condition often heralds overcrowding because there is an apparent lack of space in such places. Adequate space is an essential requirement to achieve the basic needs of privacy for tenants as this would enable the creation of a pleasant home. With rooming housing as the predominant housing stock available, there is the tendency that such accommodation could have a negative impact on children regarding school performance, mental health and other health issues. This has also affected the perceived perception of the respondents in these cities as evident in the rating of the physical characteristics of the neighbourhood as 'Low' in Fig. 1.

Table 3. Types of dwelling units in the study area

\begin{tabular}{llll}
\hline & \multicolumn{3}{c}{ Location/percentage (\%) } \\
\cline { 2 - 4 } & Yenagoa & Amarata & Ekeki \\
\hline Dwelling Type & 3.1 & & 3 \\
\hline Duplex & 3.9 & 2.9 & 3 \\
Flat & 2.9 & 4.5 & 4.4 \\
Semi-Detached (Bungalow) & 4.1 & 3.5 & 3.6 \\
Detached (Bungalow) & 54.5 & 5 & 52.2 \\
Rooming House (Courtyard) & 19 & 50.1 & 22.3 \\
Rooming House (Wagon) & 5 & 21 & 3.5 \\
Family Compound Housing & 6 & 4 & 7 \\
Traditional & 1.5 & 8 & 1 \\
Other & 100 & 1 & 100 \\
Total & \multicolumn{1}{c}{ Source: Fildtip 2020} & \\
\hline
\end{tabular}

Source: Fieldtrip 2020 


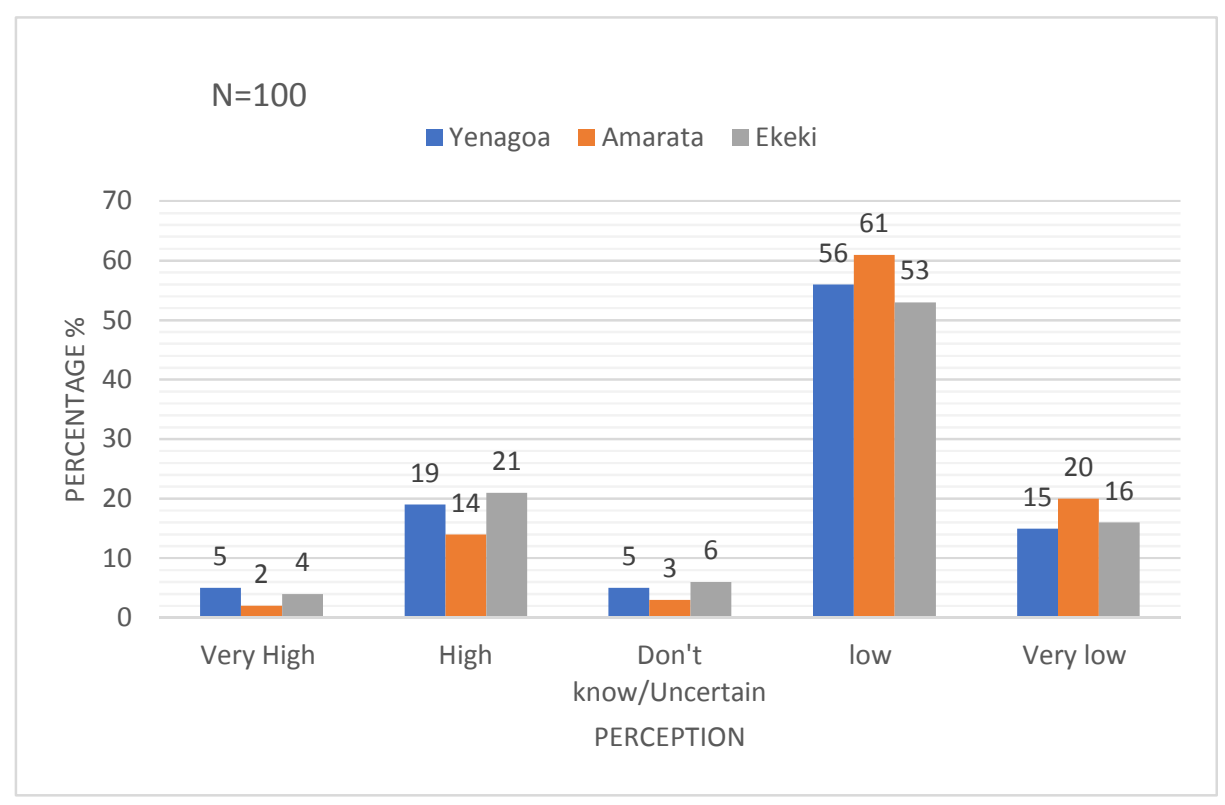

Fig. 2. Perceived Neighbourhood Rating (PNR)

Source: Field trip 2020

\subsection{Social Domain}

In the opinion of [30], the social domain in the QoL narrative is viewed from dual perspectives on the social spectrum; social support and social contact. This indicates that individuals with active social lives are much healthier than individuals without any form of active social lives who remain isolated as this might lead to depression and other health challenges. Communal living in the form of social groups depends on factors like abilities, interests and age of individuals. Social domain reiterates the communicative circumstances that influence and are often influenced by the structure which could be in the form of institutional, power-aligned and social context. Social domains are sociolinguistic contexts with three significant dimensions based on the location, participants and topic that are subject to societal definition [33]. Some social indicators represent 'measurements and other forms of evidence that enable us to assess where we stand and are going with respect to our values and goals, and to evaluate specific programs and their impact' [34]. Instances of social domains include the domains of government, school, family, religion and workplace. It is viewed as a definable political or social or community or religious group ranging from family through neighbourhood or village or a sports team or workplace, city, regional alliance or nation-state [35].

\subsection{Place of Origin}

Place of origin is an inherent subset in the social domain just like the location of participants. It engenders social interaction among respondents, enables the identification of indigenous participants and those who are not indigenous to the study area regarding their perception and rating. Available data evinced that $28 \%$ of the respondents were indigenous to the study area, while $72 \%$ of the respondents are not indigenous to the study area. This is an indication that there is a sustained social interaction among indigenous and non-indigenous residents in the study area. The second layer of information indicates that most of the non-indigenous residents are a diverse mix from several states of Nigeria who are attracted to the state due to its oil and gas producing status to eke out a living. Place of origin of respondents in the study area as evident in the research represented in Fig. 2 is the average percentage across the entire study area; Yenegoa, Amarata and Ekeki.

\subsection{Nature of Recreation}

Another salient social domain component is the well-being of the population. It is a component that comprises a wide-ranging system of social indicators aimed at assessing the quality of life of population groups [36]. Most findings regarding personal well-being studies over time have 
identified that individual well-being is a significant domain in global life satisfaction rating since it deals with interpersonal relationships which vary across cultures [37]. Data regarding the recreational wellbeing among respondents across the study area was identified with an emphasis on the nature of recreational activities respondents were interested in and participated in as well. From the data obtained, a greater percentage of respondents play football as their preference for recreation with an average of $61.3 \%$, which is closely followed by jogging as a recreation preference with an average of $11.7 \%$.
The least preferred recreation choice is the board game which comprises of a combination of draught, chess and Ludo games. Although some of the respondents have other preferences such as going to see movies in the cinema, dancing, swimming and card games. These preferences are significantly low and seem not too popular among most of the respondents.

Since playing football is the most popular form of recreation, it indicates that there is an increased social interaction among respondents as it enhances their well-being.

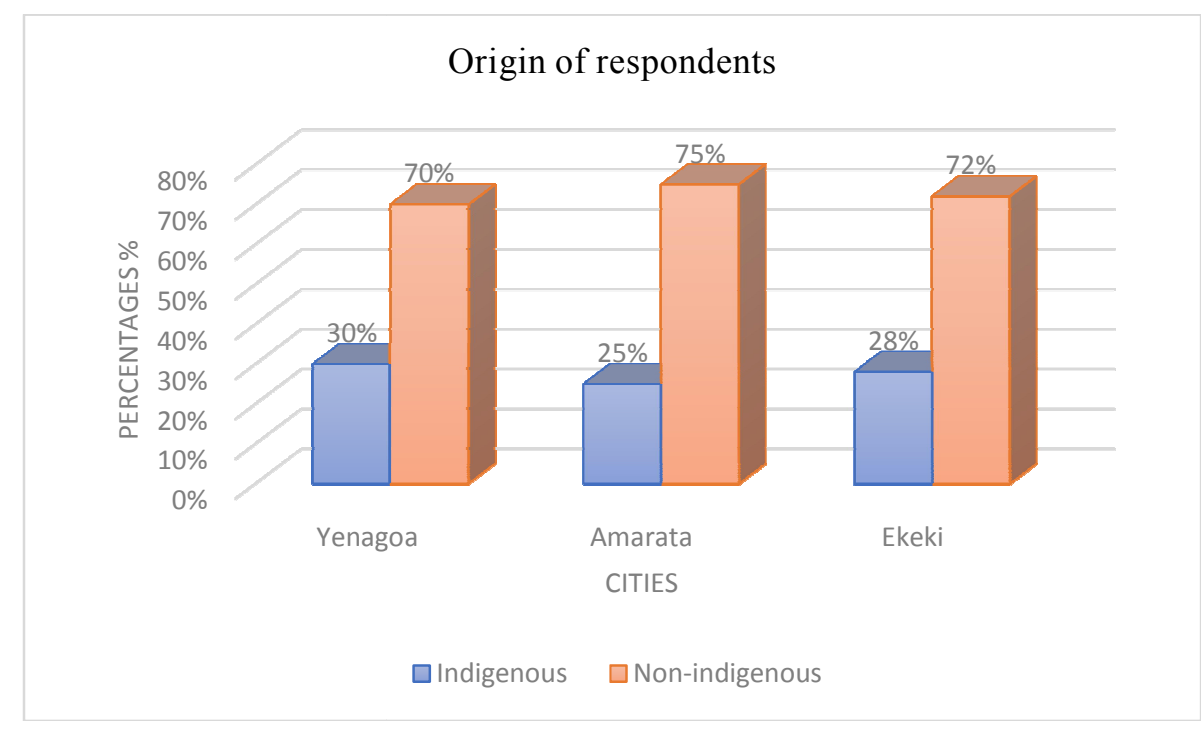

Fig. 3. Place of origin of respondents Source: Field trip 2020

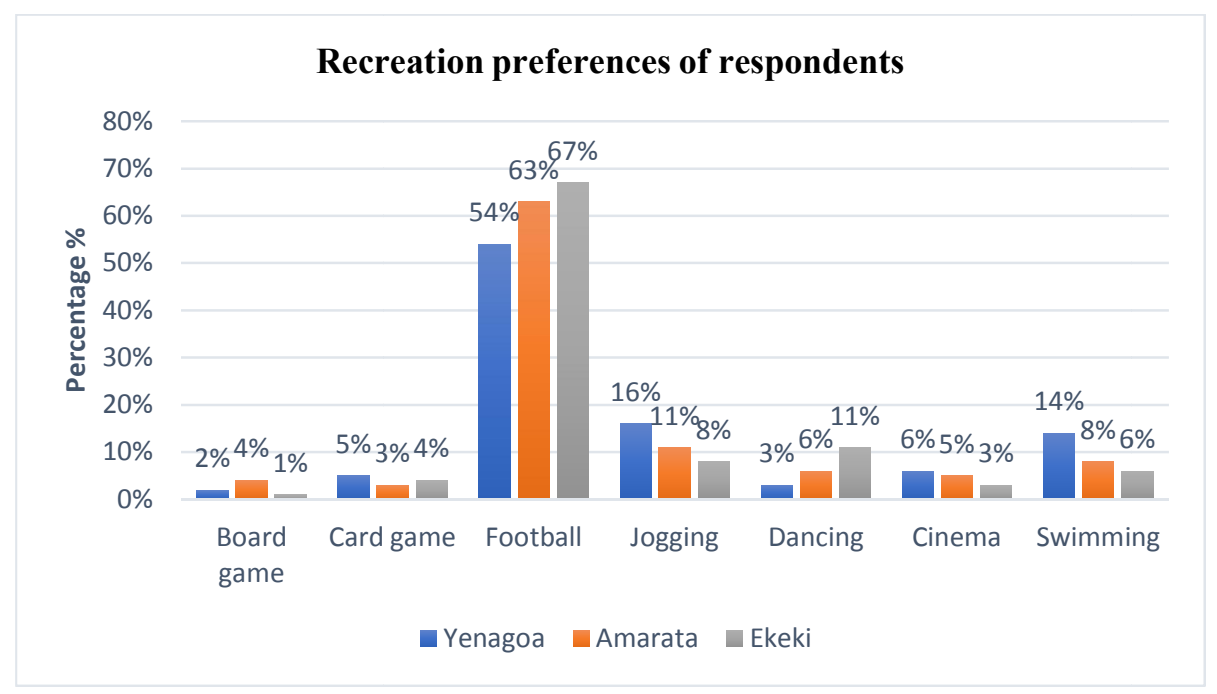

Fig. 4. Recreational preferences of respondents

Source: Fieldtrip, 2020 


\subsection{Economic Domain}

Income and conducive environment are key conditions that affect the QoL of urban residents because it has an impact on their wellbeing. Globally, functional cities often provide opportunities for residents to engage in economic activities such as employment and access to other economic resources to enhance the prospects of economic growth over time. Such functional cities provide access to urban social services and essential urban infrastructure away from the rural areas and these services and infrastructure also serve as determinants of QoL in some developing economies [38]. Economic indices in quality of life discourses are essential to comprehend the human quality of life as it enables the making of informed policy decisions that could further elucidate on a society's quality of life in addition to how specific indicators influence well-being. In defining quality of life, some limitations exist because it relies entirely on economics and the capacity of people to acquire the services that they choose from and marketplace goods. Economic progress in some instances does not guarantee the absence of crime rather it could be thought to be inversely correlated with some strands of quality of life such as healthy environment and/or leisure time [18].

Data regarding the employment status of respondents indicate that cumulatively $45 \%$ of respondents across the three cities are unemployed. Phenomenal as it is, the data indicate an underlying myriad of challenges that portends for the study area despite being an oil and gas producing state in Nigeria. The World Economic Forum in 2014 report highlighted inherent challenges occasioned by youth unemployment as it could lead to social unrest, extremism and destruction of the prospect of sustainable growth. Personal observations from the study area indicate that unemployment does not only lead to economic retrogression, rather, it also has a plethora of psychological challenges like depression, poverty, anxiety, stress and surges in suicidal and criminal thoughts. Suicidal thought processes are prevalent among unemployed youths in the study area because they display violent characteristics such as intense aggression, quick temper and irrational agitation over every minor altercation. Bell and flower [39] have linked unemployment as the causal factor of low life satisfaction and adversative health conditions among youth such as palpable unhappiness.

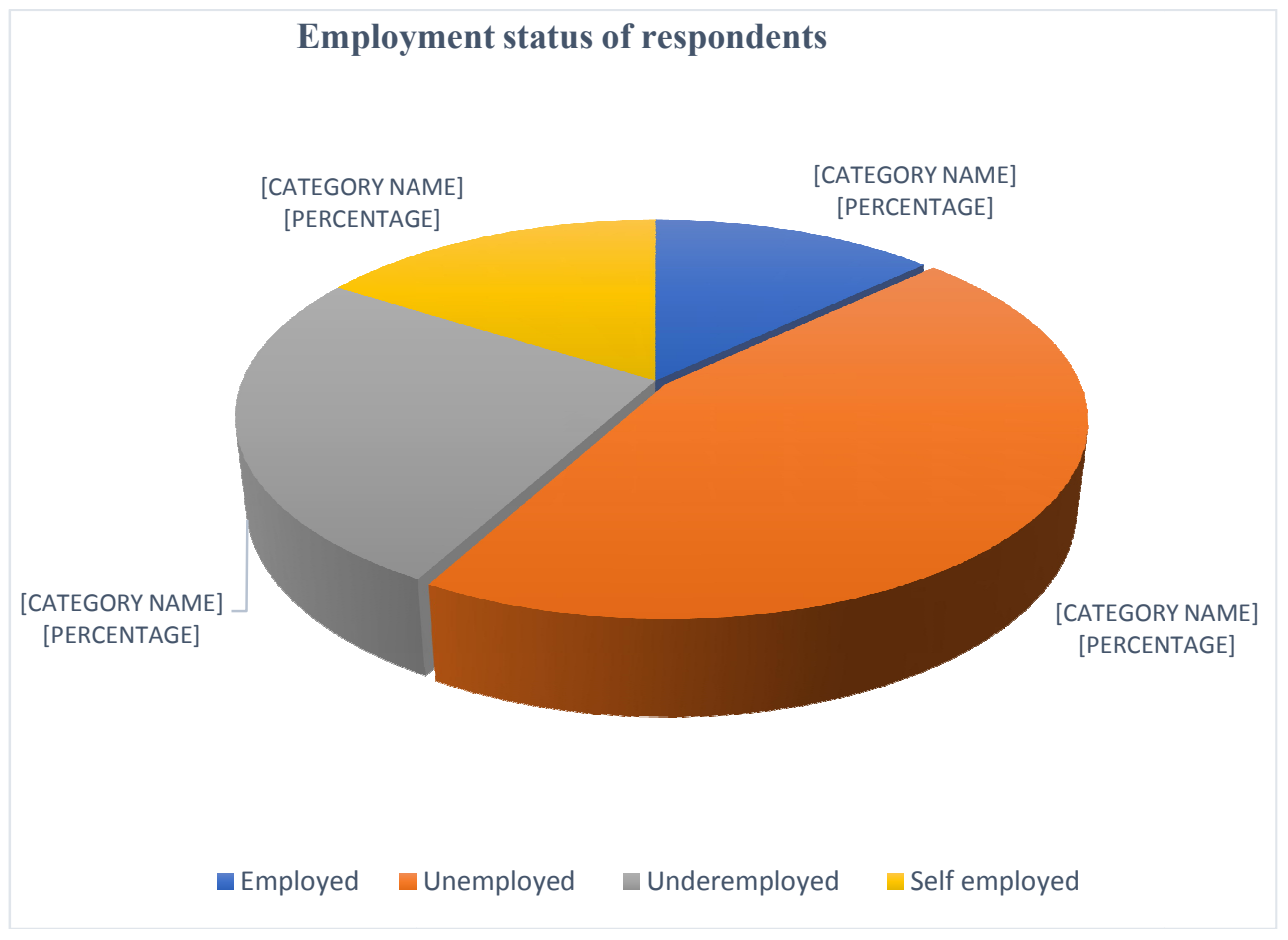

Fig. 5. Employment status of respondents Source: Fieldtrip, 2020 


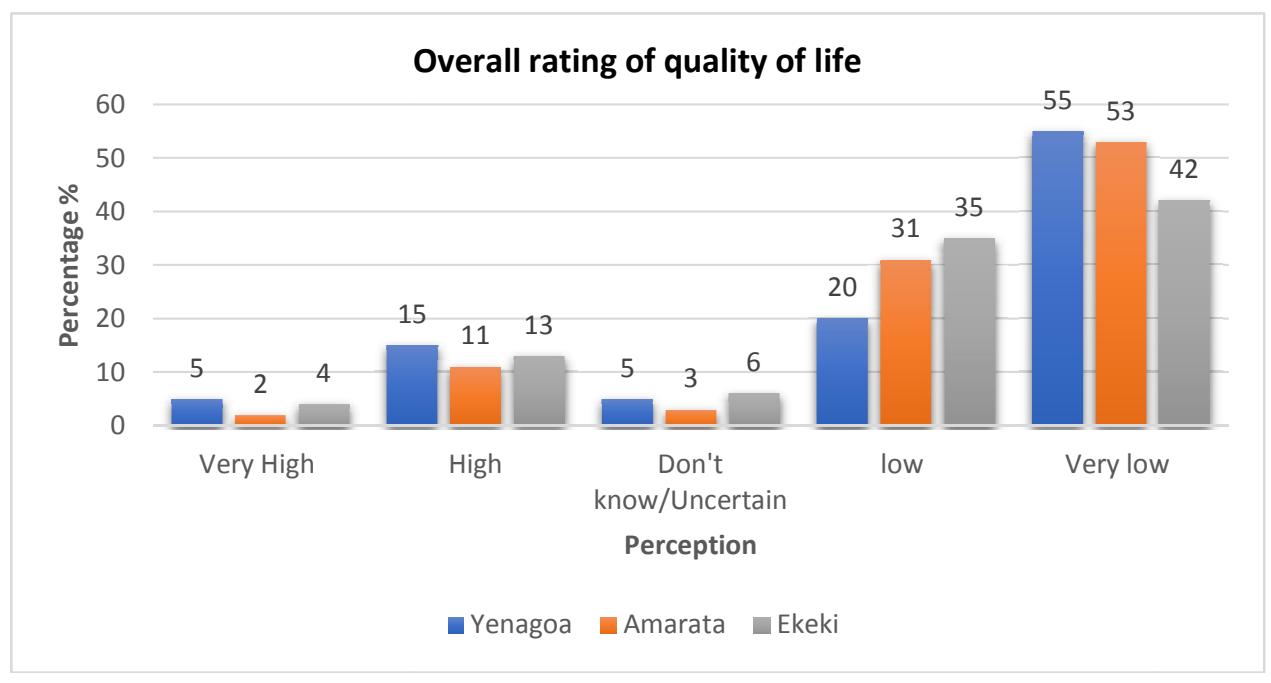

Fig. 6. Overall rating of neighbourhood quality of life Source: Fieldtrip 2020

\subsection{General Assessment of Quality of Life}

Part of the goal of this study was to evaluate the overall quality of life of residents in the neighbourhoods of Yenagoa, Amarata and Ekeki urban towns. To ascertain this, respondents were asked to rate on a Likert scale the overall quality of life of their neighbourhoods in their respective cities as evident in Fig. 5. Indications from available data evinced that cumulatively $50 \%$ of respondents across the three cities rated the quality of life in their neighbourhood as very low. Such a low rating further indicates a palpable disconnect between the government and the governed in an enclave where oil and gas resources are abundant, yet quality of life is perceived to be very low from residents. Implicitly, low quality of life in an urban area inundated with oil and gas resources as the study area is an apparent indicator of a failed social support system where social capital has been related to the background.

\section{CONCLUSION}

The study was set out to identify and highlight the declining urban quality of life of residents in an oil and gas producing state in Nigeria as evident in Yenagoa and select contiguous neighbourhoods. The study highlighted the physical, social and economic domains of quality of life in relation to the perception of residents regarding the deplorable housing conditions, inadequate space and menacing unemployment status. As it stands the results of this research reflects what obtains in other cities across the
Niger Delta with similar characteristics of hosting to oil and gas multinationals. As evident in previous studies, Dudwick et al. [2] reiterated that oil and gas bearing communities that are inundated with oil wealth have over the years experienced abysmal socio-economic underdevelopment and deprivation. This is due to an existing subtly organised systemic disequilibrium in the production conversion paradigm between the government, the governed and Trans-national companies. Based on the findings of this research and data from direct personal observations, there is a palpable decline in the quality of urban life in these selected cities in a state playing host to oil and gas multinationals.

Going forward there should be improved and sustainable deliberate government intervention to ensure that housing conditions are within localised acceptable threshold as this would help to improve the overall quality of life of residents in these neighbourhoods.

Emphasis should be placed on the provision of adequate and functional recreational facilities across the study area as this would further enhance socio-physical well-being and social interaction among residents to improve the liveability and overall quality of life.

A deliberate government policy framework that would encourage industrial development and skills acquisition should be put in place to curb the surges in the unemployment rate of productive age cohorts in the study area. 


\section{CONSENT}

Written and informed participant consent was obtained and preserved by the authors.

\section{COMPETING INTERESTS}

Authors have declared that no competing interests exist.

\section{REFERENCES}

1. Keivani R. A Review of the main challenges to urban sustainability. International Journal of Urban Sustainable Development. 2010;1(1-20):5-16.

2. Dudwick N, Hull K, Katayama R, Shilpi F, Simler K. From farm to firm: Rural-urban transition in developing countries. Washington, D.C., USA: The International Bank for Reconstruction and Development/ the World Bank; 2011.

3. Brown I, Ekpudjureni B. An evaluation of the quality of life of urban dwellers in selected streets in Diobu, Port Harcourt, Nigeria. Journal of Scientific and Engineering Research. 2016;3(6):238-251.

4. Brown I, Eyenghe T. An evaluation of the effects of petroleum exploration and production activities on the social environment in Ogoni Land, Nigeria. International Journal of Scientific \& Technology Research. 2015;4(4):273-282.

5. Bayelsa State Government Yenagoa Master Plan 2004. Port Harcourt, Nigeria: A Sand P-Harcourt Adukeh Associates. 2004;7-28.

6. Marans, Stimson, (Eds.) Investigating quality of urban life: Theory, methods, and empirical research. Social Indicators Research series, Springer, Netherlands. 2011;45:4.

7. Lavdaniti M, Tsitsis NN. Definitions and conceptual models of quality of life in cancer patients. Health Science Journal. 2015;9(2).

8. Heather D. Hill welfare as maternity leave? Exemptions from welfare work requirements and maternal employment. Soc Serv Rev. 2012;86:37-67.

9. Eva $P$, Alex D, Yannis P. Defining the quality of urban life: Which factors should be considered? Proceedings of the 51st European Congress, Barcelona, Spain.
European Regional Science Association; 2011.

10. Costanza R, Fisher B, Ali S, Beer C, Bond L, Boumans R, Gayer DE. An integrative approach to quality of life measurement, research, and policy. SAPI EN. S. Surveys and Perspectives Integrating Environment and Society. 2008;(1.1).

11. Lotfi S, Amin F, Husain H, Ahmad P. A study of urban quality of life in a developing country. Journal of Social Sciences. 2011;7(2):232-240.

12. Santos, Martins. Intra-Urban Disparities in the Quality of Life of Porto: A Spatial Analysis Contribution; 2014.

13. Sarah AM. Neighbourhood Urban Quality of Life: Guidelines for Urban Planning and Development of New Assessment Tool (Doctoral dissertation); 2012.

14. Kladivo P, Halás M. Quality of life in an urban environment: A typology of urban units of olomouc. Quaestiones Geographicae. 2012;31(2):49-60.

15. Ventegodt S, Merrick J, Anderson NJ. Quality of life theory i. the IQOL theory: An integrative theory of the global quality of life concept. The Scientific World Journal. 2003;3:1030-1040.

16. Garau C, Pavan VM. Evaluating urban quality: indicators and assessment tools for smart sustainable cities. Sustainability. 2018;10(575):1-18.

17. McCrea R. Urban quality of life: Linking objective dimensions and subjective evaluations of the urban environment; 2007.

18. Diener E, Suh E. Measuring quality of life: Economic, social, and subjective indicators. Social Indicators Research. 1997;40(1-2):189-216.

19. El Din SH, Shalaby A, Farouh HE, Elariane SA. Principles of urban quality of life for a neighbourhood. Hbrc Journal. 2013;9(1): 86-92.

20. Myers D. Building knowledge about quality of life for urban planning. Journal of the American Planning Association. 1988; 54(3):347-358.

21. Massam BH. Quality of life: Public planning and private living. Progress in Planning. 2002;58:141-227.

22. Wokekoro E, Owei OB. An assessment of residential quality of life in informal settlements in Port Harcourt Municipality. Journal of Humanities and Social Science (IOSR-JHSS). 2014;19(3):11 - 26 
23. Giannias DA. Quality of life in southern Ontario. Department of Economics, University of Crete, Athens Greece; 1996. Available:www.findarticles.com Accessed 15/4/2020

24. United Nations Human Settlements Programme (UN-HABITAT) State of the world's cities 2012/2013: Prosperity of cities; 2014.

25. Sheng KY. The Challenges of Promoting Productive, Inclusive and Sustainable Cities Urbanization in South-East Asia. 2010;145-162.

26. Seik FT. Subjective assessment of urban quality of life in Singapore (1997-1998). Habitat International. 2000;24(1):31-49.

27. Sedaghatnia S, Lamit H, Amir G, Mohamad SB. An evaluation of residents' quality of life through neighbourhood satisfaction in Malaysia. Environmental Management and Sustainable Development Macrothink Institute. 2013; 2(1).

28. Naude W, Rossouw S, Krugell W. The quality of metropolitan city life in South Africa. Work well, research unit for people, policy and performance and school of economics, risk-management and international trade, North-West University, Potchefstroom, South Africa; 2006.

29. Amao F. Quality of life of poor residential neighbourhoods in Oshogbo, Nigeria. World Academy of Science, Engineering and Technology. International Journal of Social, Education, Economics and Management Engineering. 2014;8(4):881884.
30. Medhorizone. Quality of Life Factors; 2018. Available:www.medhorizons.com/quality.ht ml

Retrieved $10^{\text {th }}$ March 2020

31. Streimikiene D. Quality of life and housing. International Journal of Information and Education Technology. 2015;5(2):140.

32. Myers D, Baer WC, Choi SY. The changing problem of overcrowded housing. Journal of the American Planning Association. 1996;62(1):66-84.

33. Fishman JA, Cooper RL, Newman RM. Bilingualism in the Barrio Indiana University. 1971;1.

34. Bauer RA. Social indicators; 1966.

35. Spolsky B. Language policy. Cambridge: Cambridge University Press; 2004.

36. Diener E. Guidelines for national indicators of subjective well-being and ill-being. Applied Research in Quality of Life. 2008; 1:151-157.

37. Casas F. Subjective social indicators and child and adolescent well-being. Child Indicators Research. 2011;4(4): 555-575.

38. Fellmann JD, Getis A, Getis J, Malinowski JE. Human Geography: Landscapes of Human Activities. (Eighth Edition), New York, USA: McGraw-Hill Companies Inc., USA. 2005;428-437.

39. Bell D, flower BD. What should be done about rising unemployment in the OECD? Discussion Paper No. 4455 (Bonn, IZA). 2010. Youth unemployment: Déjà vu? Discussion Paper No. 4705 (Bonn, IZA); 2009.

(c) 2020 Brown and Dapa; This is an Open Access article distributed under the terms of the Creative Commons Attribution License (http://creativecommons.org/licenses/by/4.0), which permits unrestricted use, distribution, and reproduction in any medium, provided the original work is properly cited. http://www. sdiarticle4.com/review-history/59209 